\title{
Development of Composition Brake Shoe for Reducing Heat Load to Wheel Tread with Keeping Brake Performance
}

\author{
Shin-ichi SAGA \\ Yasushi KARINO \\ Brake Control Laboratory, Vehicle Control Technology Division \\ Akihiro HAGA \\ Jun-ichi NAKAHASHI \\ Vehicle Dynamics Laboratory, Vehicle Structure Technology Division
}

\begin{abstract}
In rail vehicles using composition brake shoes, the friction coefficient between the wheel and the brake shoe tends to decrease under wet conditions. In order to maintain the braking force, it is common practice to insert a metallic block to remove the water. However, the metallic block causes a localized temperature rise on the wheel tread surface under dry conditions, which is one of the factors in wheel tread damage and concave wheel tread wear. A composition brake shoe was developed to suppress the temperature rise of the wheel tread and, at the same time, maintain the brake force under wet conditions. This paper summarizes the evaluation of the composition brake shoe performance in dynamo tests, running tests and long-term durability running tests, including verification that the developed brake shoe has controlled concave wear.
\end{abstract}

Keywords: brake performance, composition brake shoe, heat load, metallic block, elastic material, concave wear

\section{Introduction}

In the rail vehicles that use composition brake shoes for the wheel tread, the friction coefficient between the wheel and the brake shoe tends to decrease under wet conditions, and the brake force falls. In particular, brake performance in "short train sets" consisting of one or two vehicles falls dramatically, since ridding water of the rail surface by preceding vehicles is not expectable.

Although a metallic block has previously been inserted to counteract the decline in friction coefficient under such wet conditions, this metallic block rubs excessively on the wheel tread under dry conditions, and causes a localized increase in the temperature of the wheel tread. Such heat load is one of the factors that produce the wheel tread damage referred to as "heat crack and concave wear of the wheel tread" [1]. For this reason, a composition brake shoe that does not use metallic blocks to restrict increases in the temperature of the wheel tread and maintains brake performance under wet conditions has been developed.

This paper summarizes the performance evaluation for the composition brake shoe in dynamo tests, running tests and long-term running tests, including verification of the fact that the developed brake shoe has controlled concave wear.

\section{Stress analysis of brake shoe}

\subsection{Analysis model}

Three analysis models were used: the conventional composition brake shoe with insertion of the metallic block, the elastic material type, and the elastic structure type as shown in Fig. 1. The latter two elastic types are devised so that the contact surface pressure is equalized. Stress analysis was carried out on the conditions shown below. Each physical-property value is shown in Table 1.

- The analysis technique: continuum two-dimensional elastic analysis

- Force condition: uniformly distributed load to four shoe heads

- Pressing force: $4.9 \mathrm{kN}, 9.6 \mathrm{kN}, 13.6 \mathrm{kN}$

- Boundary condition: wheel is rigid and the displace-

Table 1 Physical-property value in analysis

\begin{tabular}{|l|l|l|l|}
\hline \multirow{2}{*}{ Shape } & Parts & $\begin{array}{l}\text { Compressive elasticity } \\
\text { modulus }(\mathrm{GPa})\end{array}$ & Poisson's ratio \\
\hline \multirow{3}{*}{ Conventional type } & Back plate & 206 & 0.30 \\
\cline { 2 - 4 } & Base material A & 2.1 & 0.30 \\
\cline { 2 - 4 } & Metallic block material & 10 & 0.21 \\
\hline \multirow{2}{*}{$\begin{array}{l}\text { Elastic material type } \\
\text { Elastic structure type }\end{array}$} & Back plate & 206 & 0.30 \\
\cline { 2 - 5 } & Base material B & 1.9 & 0.39 \\
\cline { 2 - 5 } & Elastic material & 1.5 & 0.49 \\
\hline
\end{tabular}




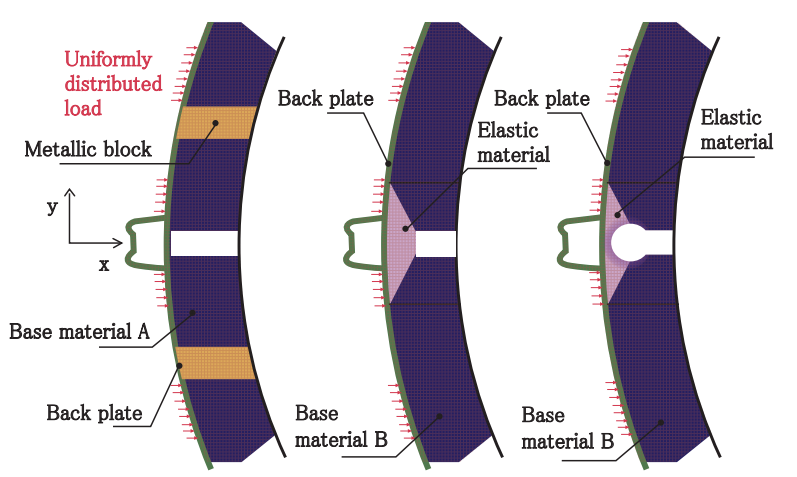

$\begin{array}{lll}\text { (a) Conventional type } & \text { (b) Elastic material type } & \text { (c) Elastic structure type }\end{array}$

Fig. 1 Analysis model

ment is restrained in the $\mathrm{x}$-direction on the contact border plane.

In addition, the following three demands are taken into consideration in devising a new composition brake shoe.

- To suppress local concentration of the contact surface pressure by changing uniform compressive elasticity modulus.

- To compound the smashed block (hard particle is included) at the base material uniformly in order to equalize the contact with wheel tread.

- To arrange elastic material with comparatively low compressive elasticity modulus in the central part in order to compensate for the contact surface pressure decrease at both shoe ends.

\subsection{Analysis results}

The analysis result for the contact surface pressure of wheels with the pressing force of $13.6 \mathrm{kN}$ is shown in Fig. 2 . Since the compressive elasticity modulus of the metallic

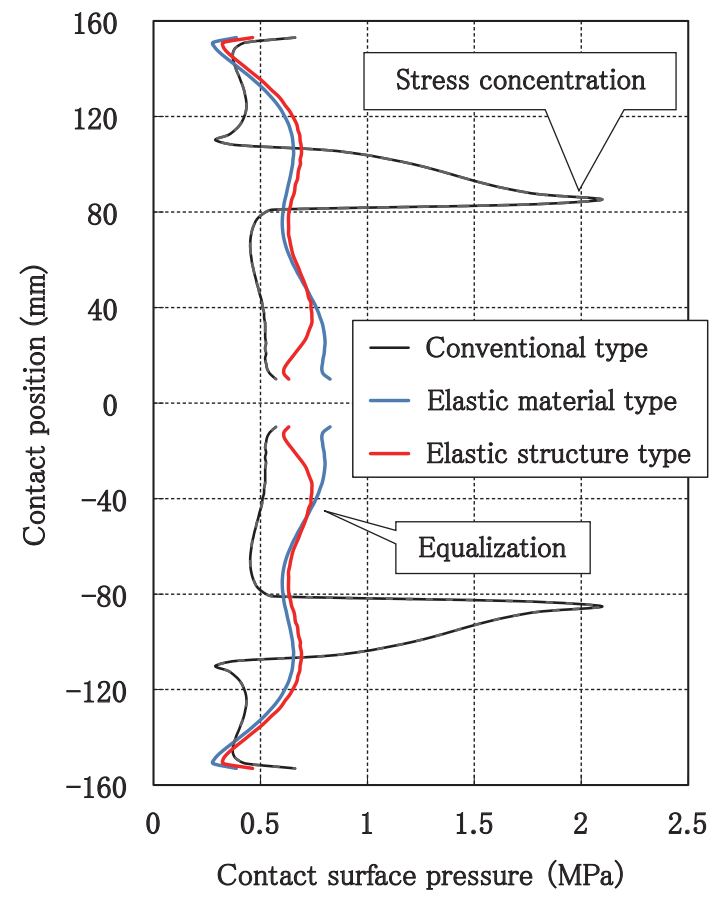

Fig. 2 Analysis of contact surface pressure (pressing force $13.6 \mathrm{kN}$ )
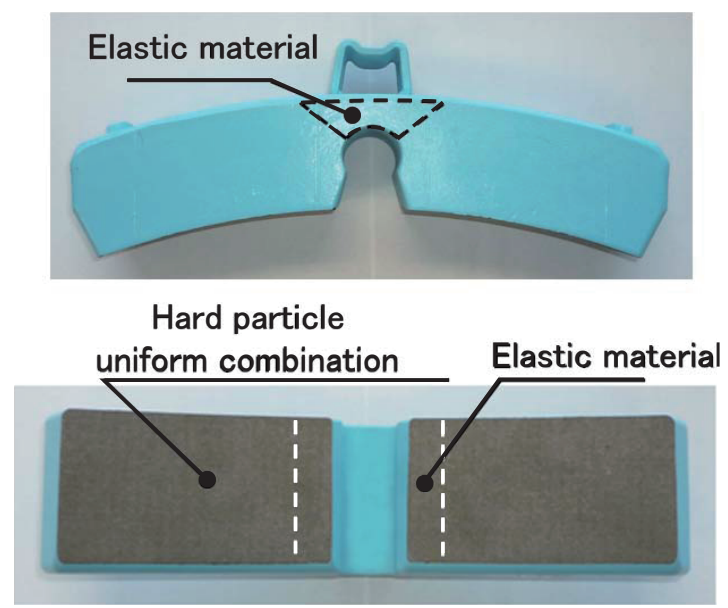

Fig. 3 Trial manufacture of elastic structure composition brake shoe

block in a conventional shoe is approximately five times greater than in the base material, stress is concentrated in the block part. On the other hand, the developed brake shoe mitigates the concentration of stress by means of the elastic material placed in the central part and the equalization of the compressive elasticity modulus. Furthermore, the elastic structure type is more uniform with regard to the contact surface pressure in the central part than the elastic material type. Hence development and the trial manufacture were conducted based on the elastic structure type (Fig. 3).

\section{Dynamo test}

Two kinds of elastic structure type composition brake shoes were manufactured. Developed shoe A is designed so as to make its friction coefficient higher than that of the conventional shoe and developed shoe B is designed so as to make its friction coefficient equal to that of the conventional shoe. A dynamo test was carried out under the conditions shown below. The test condition was set based on the assumption that the vehicle weight was $480 \mathrm{kN}$ (49 tf), and the initial velocity and the classification of a braking method were based on the conditions provided in Japanese Industrial Standard: JIS E4309 (composition brake shoe requirements for quality).

- Moment of inertia: $11.8 \mathrm{kNm}^{2}\left(1200 \mathrm{kgm}^{2}\right)$

- Wheel diameter: $860 \mathrm{~mm}$

- Pressing system: dual holding

- Rubbing condition: $70 \%$ or more

- Brake start temperature: $60^{\circ} \mathrm{C}$ or less

\subsection{Average friction coefficient}

The average friction coefficient is shown in Fig. 4. The friction coefficient of developed shoe $\mathrm{A}$ is improved by 10 to $40 \%$ compared with the conventional shoe in all test conditions. The friction coefficient of developed shoe B is approximately the same as that of the conventional shoe in all test conditions. These characteristics indicate that the desired friction coefficient is obtained by correctly adjusting the material composition of the shoe properly. 


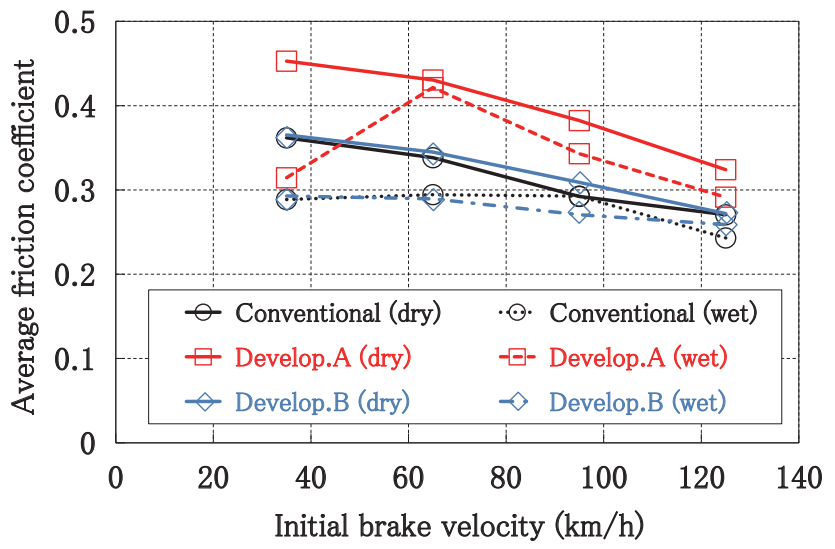

Fig. 4 Average friction coefficient (dry, wet, pressing force $9.8 \mathrm{kN}$ )

Generally, replacing brake shoe requires the brake cylinder pressure to be set up again in many cases, as the coefficient of friction differs. However, the developed article has high flexibility in terms of material composition and is able to set the friction coefficient equivalent to the shoe currently used, its replacement is easy.

\subsection{Results for temperature}

The wheel tread temperature at the time of braking under dry conditions was measured using a high speed thermal camera (Fig. 5). The temperature distribution for each time is shown in Fig. 6 . While the conventional product demonstrated a localized temperature increase of $500^{\circ} \mathrm{C}$ or more, developed shoe B obtained a uniform temperature distribution, and the highest temperature was reduced to approximately $300^{\circ} \mathrm{C}$.

Here, the wheel tread temperature using different type of shoes including sintered alloy shoes and alloy cast iron shoes is compared. In the dynamo test in which the pressing force of the shoe was adjusted so as to obtain an emergency brake distance of 500 to $550 \mathrm{~m}$, the temperature of the wheel tread was measured under braking conditions.

The high speed thermal camera acquires the thermal images of about 30 frames per second, and the thermal data at about 60000 points per image. The histogram of the acquired temperature during the braking is shown in Fig. 7. As a result of this process, a significant localized

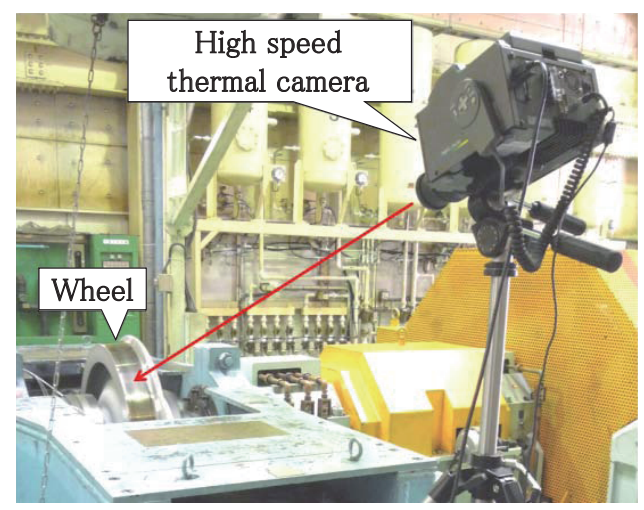

Fig. 5 Installation situation of the high speed thermal camera

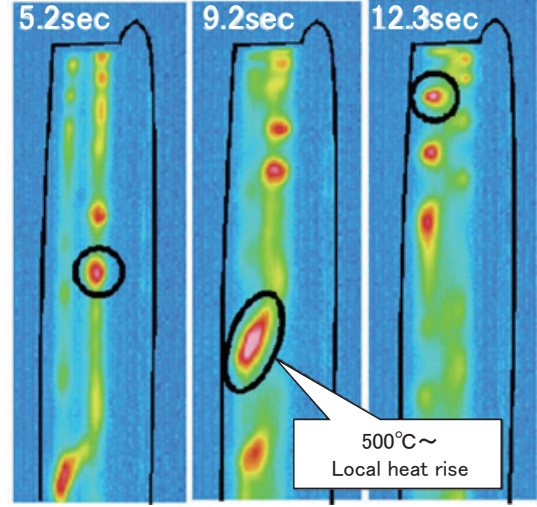

(a) Conventional
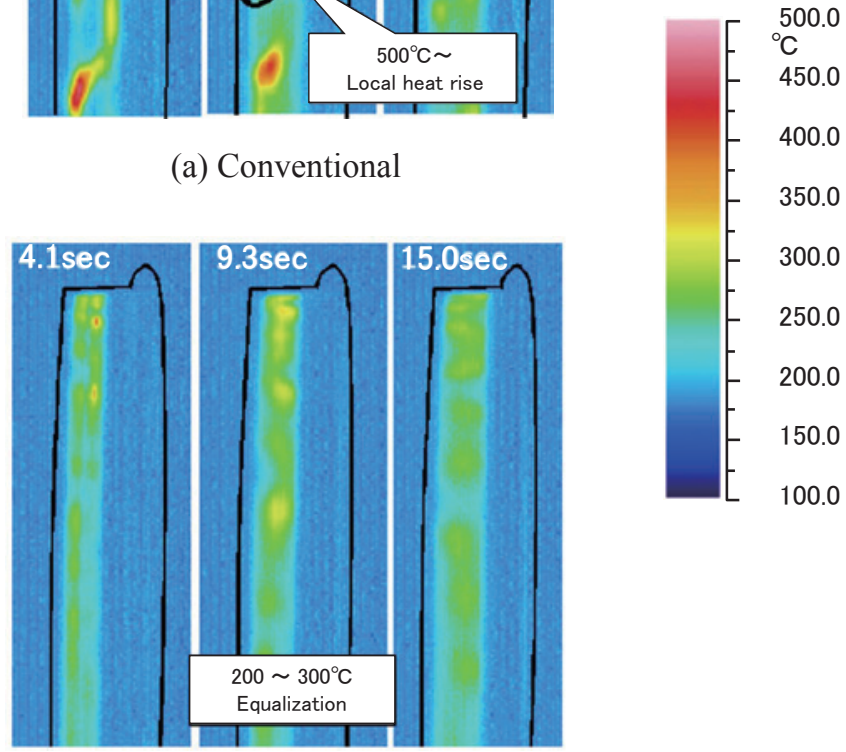

(b) Developed shoe (B)

Fig. 6 Instantaneous temperature of the wheel tread at braking $(125 \mathrm{~km} / \mathrm{h}, 14.7 \mathrm{kN})$

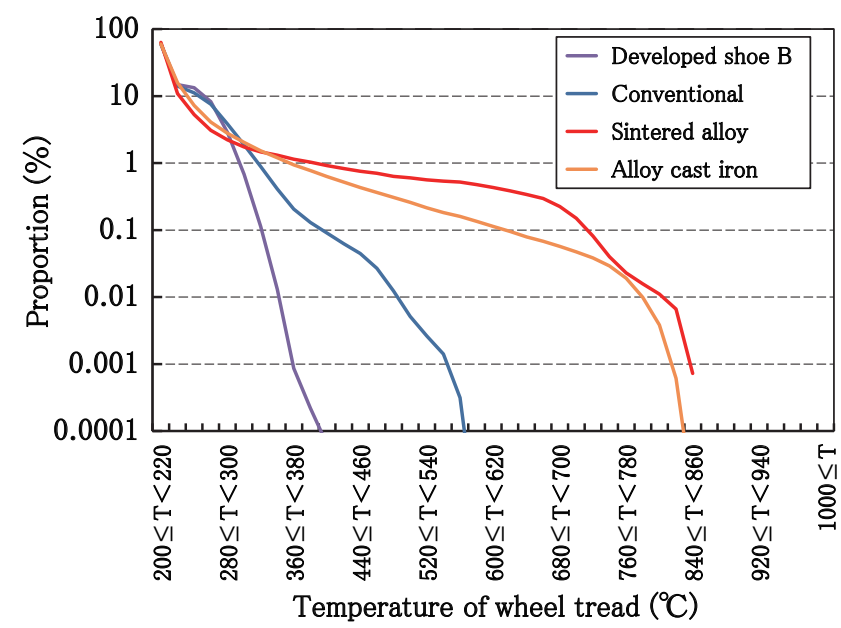

Fig. 7 Temperature distribution of the wheel tread

temperature increase of more than $800^{\circ} \mathrm{C}$ was observed for the sintered alloy shoe and the alloy cast iron shoe.

Regarding the rate exceeding $300^{\circ} \mathrm{C}$, the undesirable temperature of the wheel, it is in the conventional composition shoe approximately $4 \%$, the developed shoe B approximately $1 \%$, the sintered alloy shoe approximately $15 \%$ and the alloy cast iron shoe approximately $10 \%$ respectively. In 
particular, shoe B has a control of the highest temperature and a reduction effect of high-temperature range.

\section{Running test}

\subsection{Developed shoe A}

A brake performance running test was carried out using the conventional shoe and developed shoe A. The test train set is shown in Fig. 8. Watering on one axle or two axles occurred at a rate of 4 liters/minute. The running test conditions were as follows.

- Initial velocity: $30,60,90,110 \mathrm{~km} / \mathrm{h}$

- Brake notch: B7 (maximum service brake), EB (emergency brake)

- Rail conditions: dry, wet

- Brake shoe: conventional, developed shoe A

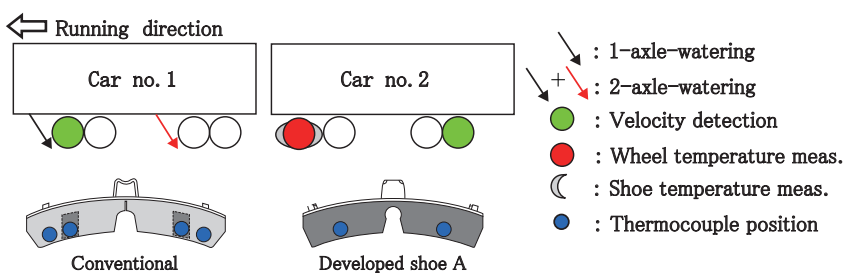

Fig. 8 The running test train for the conventional shoe and developed shoe $A$

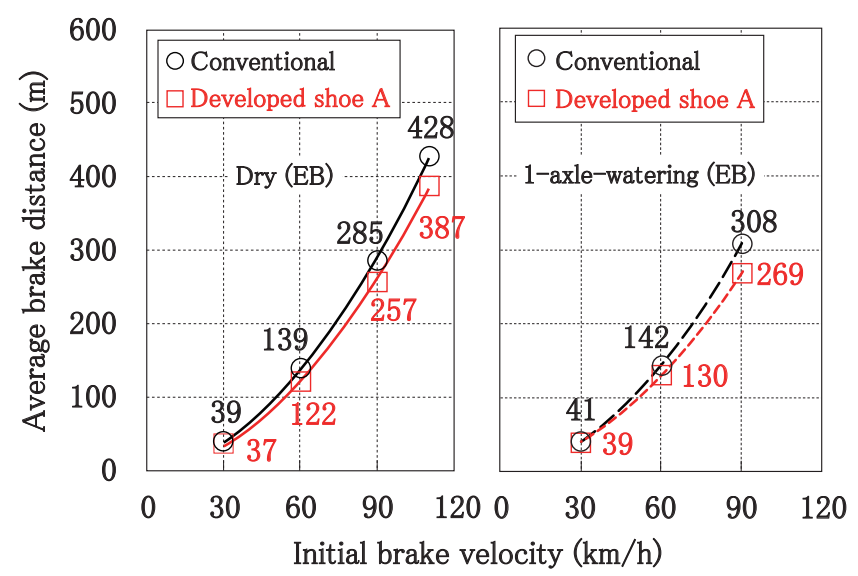

Fig. 9 Results of brake distance for 1-axle-watering

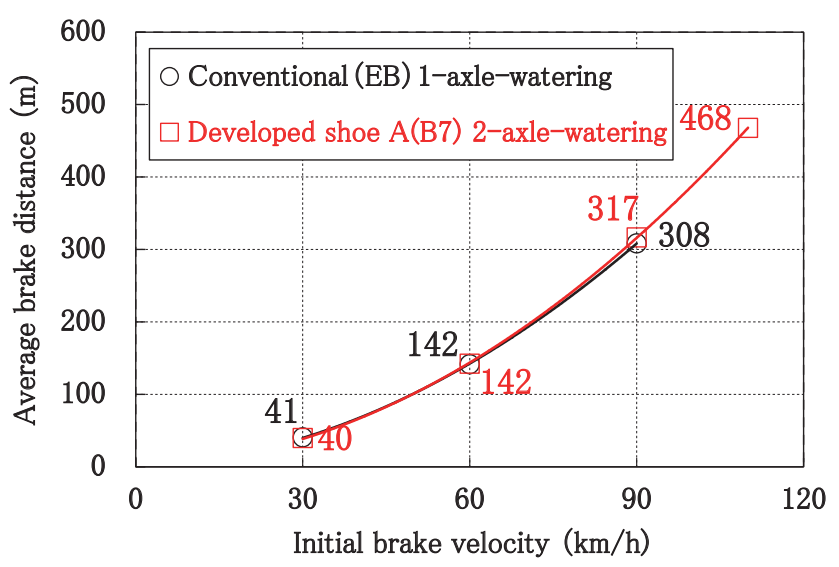

Fig. 10 Results of brake distance for 2-axle-watering
The result of the average braking distance which was obtained after compensation for the gradient and the initial velocity about the measured distance is shown in Fig. 9. For the conditions of dry and 1-axle-watering, the brake distance of developed shoe A was shortened by $10 \%$ compared with the conventional shoe. In addition, the pressing force of developed shoe A was changed from EB to B7 under 2-axle-watering conditions. It exhibited high brake performance equivalent to that of the emergency brake (EB) under the 1-axle-watering conditions of the conventional shoe (Fig. 10). However, the developed shoe A which has such high brake performance frequently generated a flat on the wheel tread.

\subsection{Developed shoe B}

A brake performance running test was carried out using developed shoe $\mathrm{B}$ which was considered not to readily generate a flat on the wheel tread. The test train set is shown in Fig. 11. Each test condition is shown below.

- Initial velocity: $30,60,90,100,110,120 \mathrm{~km} / \mathrm{h}$

- Brake notch: EB (emergency brake)

- Rail conditions: dry, wet (2-axle-watering)

- Brake shoe: developed shoe B

(1) Brake distance

The result of the average braking distance value compensated by the gradient and the initial velocity from the measured one is shown in Fig. 12. With the average value of developed shoe B under 2-axle-watering conditions, the ratio of the braking distance between the dry condition and the wet condition is suppressed to about $20 \%$ at $60 \mathrm{~km} / \mathrm{h}$, about $17 \%$ at $90 \mathrm{~km} / \mathrm{h}$, and about $6 \%$ at $120 \mathrm{~km} / \mathrm{h}$.

The maximum brake distance at $120 \mathrm{~km} / \mathrm{h}$ was 550.3 $\mathrm{m}$ under dry conditions and $550.6 \mathrm{~m}$ under 2-axle-watering conditions, which indicated that developed shoe B stopped the train within $600 \mathrm{~m}$ even under the severe 2-axle-watering rail conditions.

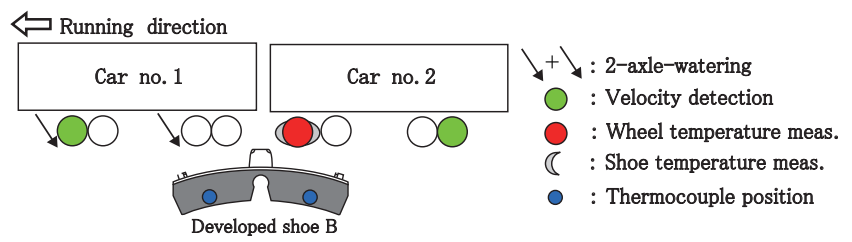

Fig. 11 The running test train for the developed shoe $B$

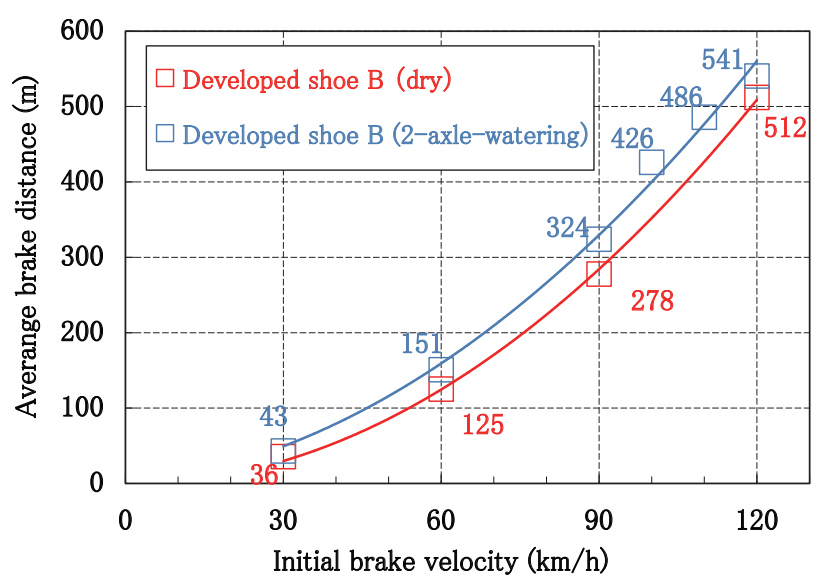

Fig. 12 Results of brake distance for 2-axle-watering 
(2) Temperature

A thermocouple was inserted at $10 \mathrm{~mm}$ below the surfaces of the shoe. The thermolabel was set in the rim of the wheel. The maximum temperature of the conventional shoe was $170^{\circ} \mathrm{C}$ (at $60 \mathrm{~km} / \mathrm{h}$ ), the developed shoe $\mathrm{B}$ was $111.2^{\circ} \mathrm{C}$ (at $120 \mathrm{~km} / \mathrm{h}$ ). All results were under $250{ }^{\circ} \mathrm{C}$. The state of the rubbing surface of developed shoe $\mathrm{B}$ after the running test was superior and the surface was without any significant damage. In addition, the maximum temperature of the wheel with the conventional shoe was $220^{\circ} \mathrm{C}$, and $170^{\circ} \mathrm{C}$ with developed shoe B. All results were below the standard temperature of $300^{\circ} \mathrm{C}$.

\section{Long-term durability running test}

A long-term durability running test was carried out using the developed shoe B in half of the bogies of a train in service. Long-term evaluation of the mitigating effect on damage was conducted based on various results from the investigations, such as wheel tread shape (Fig. 13). By using a wheel wear shape presumption tool [2], the wear shape after an $80000 \mathrm{~km}$ run was presumed and evaluated based on the wheel tread shape after a run of approx. $40000 \mathrm{~km}$, which is the usual replacement cycle for wheels.

This presumption tool holds database of several wear shape data records with different mileages, and presumes the wheel tread shape in arbitrary mileage by the linear regression of the obtained data linearly interpolated in the width-of-rim direction at intervals of $0.1 \mathrm{~mm}$.

A comparison of these presumed shapes is shown in Fig. 14. With regard to the wear shape of the wheel with the conventional shoe, a tendency of concave wear is recognized, covering the slide width of the shoe. In contrast, the developed shoe B certainly has an inhibiting effect on wheel concave wear. A long-term durability test in which the developed shoe B is installed in all the bogies of the train was carried out for a final check.

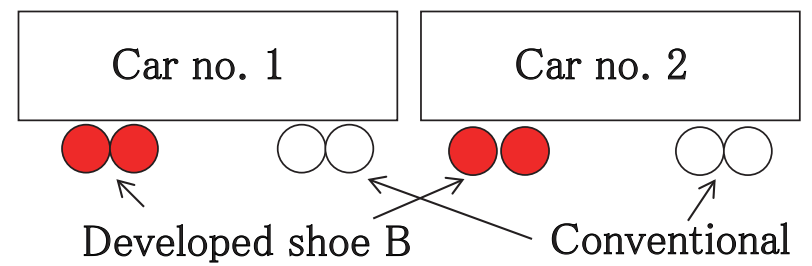

Fig. 13 The long-term durability test train for developed shoe B

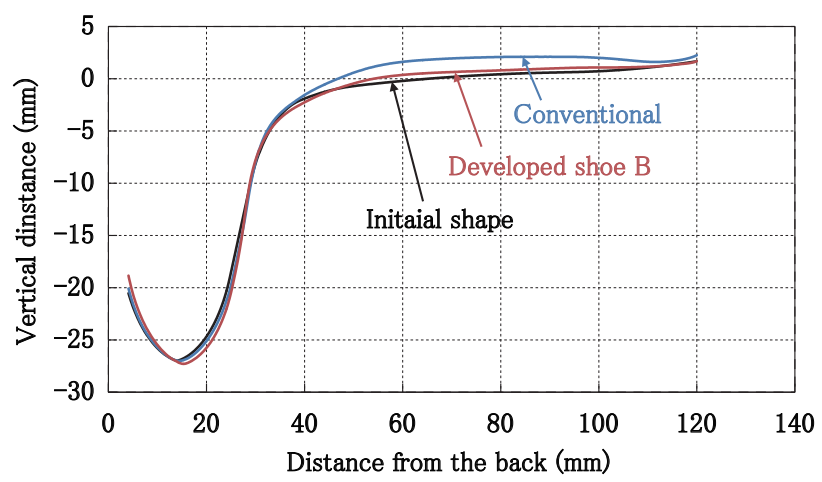

Fig. 14 The presumed tread shape at 80000 km

\section{Evaluation of running stability based on wear shape of the tread}

\subsection{Analysis condition}

When designing wheel tread shape, the curvature of the wheel tread should be smaller than that of the rail surface, to avoid an increase of hertz pressure and two-point contact. But, as the wear of the wheel or the rail progresses by the increase in accumulation of mileage or passing tonnage, the number of the junction points between the wheel and rail may become two [3].

In particular, if concave wear progresses and two-point contact occurs near the neutral point, running stability

Table 2 Analysis conditions

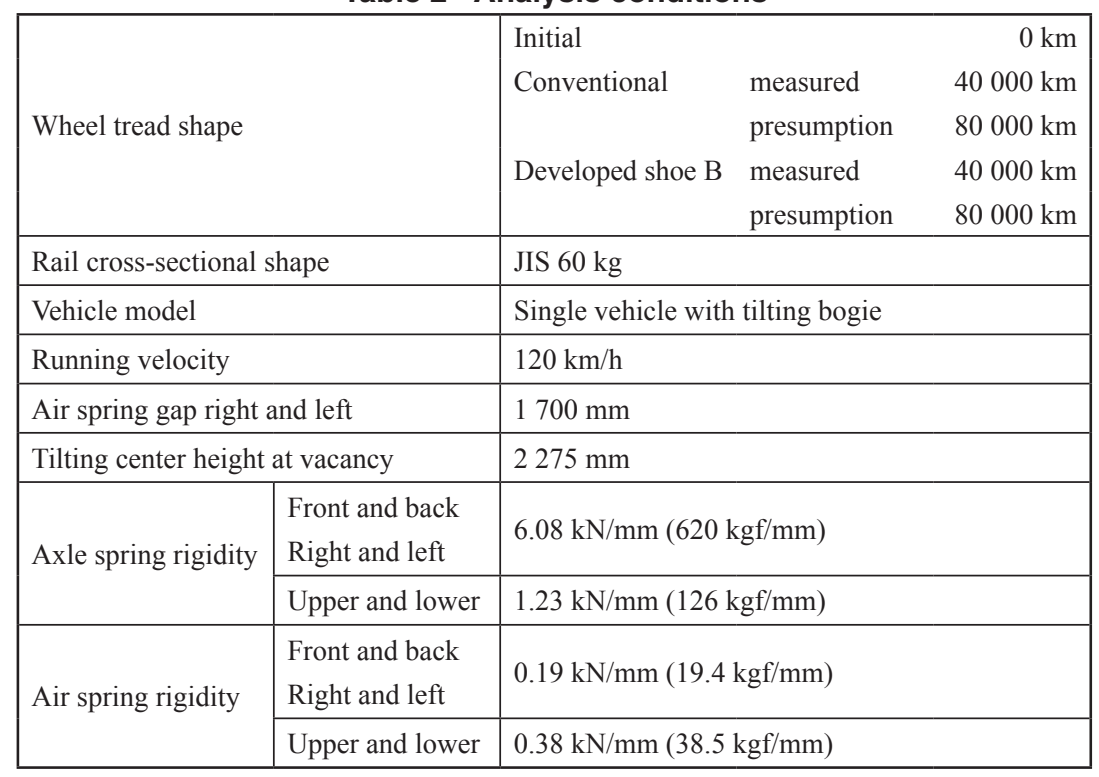


may be affected. A junction-point analysis was then conducted between the wheel and rail with consideration of the two-point contact, using the tread shape obtained from the above-mentioned survey and presumption. The running stability was evaluated based on the simulation of the vehicle motion using this result. The main analysis conditions are shown in Table 2.

\subsection{Analysis results}

Evaluation of the running stability was carried out by giving displacement $(1 \mathrm{~Hz}, \pm 3 \mathrm{~mm}, 3$ waves $)$ from the first axle to the fourth axle in a straight section at a constant velocity of $120 \mathrm{~km} / \mathrm{h}$, and the response in each type of shoe was compared in terms of the lateral vibration acceleration of the first bogie frame. The analysis result is shown in Fig. 15. In the presumed tread shape for the wheel with the conventional shoe after a run of $80000 \mathrm{~km}$, the lateral vibration acceleration of approx. $2 \mathrm{~m} / \mathrm{s} 2$ in total amplitude occurred repeatedly after the passage of displacement, which is probably a self-induced oscillation resulting from concave wear.

In contrast, in the presumed tread shape for the wheel with developed shoe B after the $80000 \mathrm{~km}$ run, the bogie frame lateral acceleration was settled immediately after the passage of displacement. Below, the power spectrum density (PSD) of the acceleration waveform for the lateral
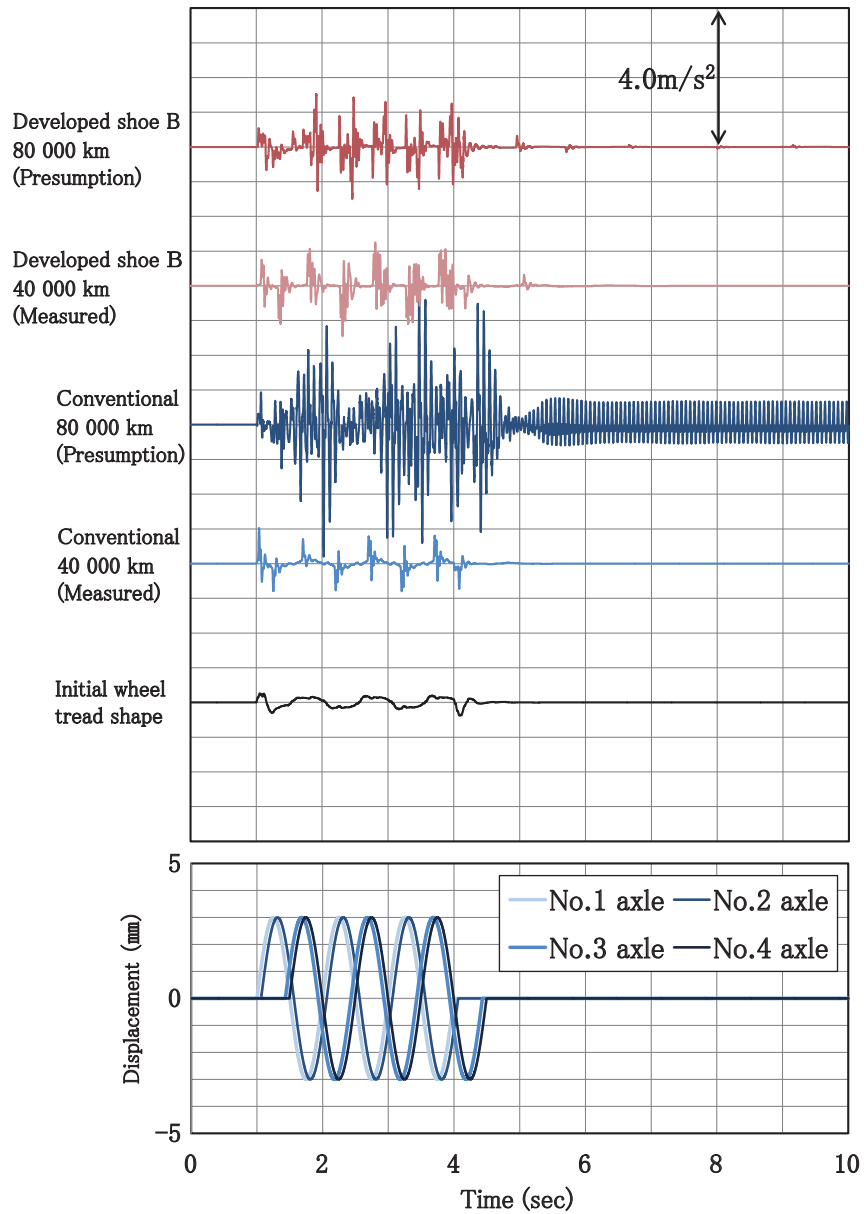

Fig. 15 Comparison of the analysis results for vibration acceleration

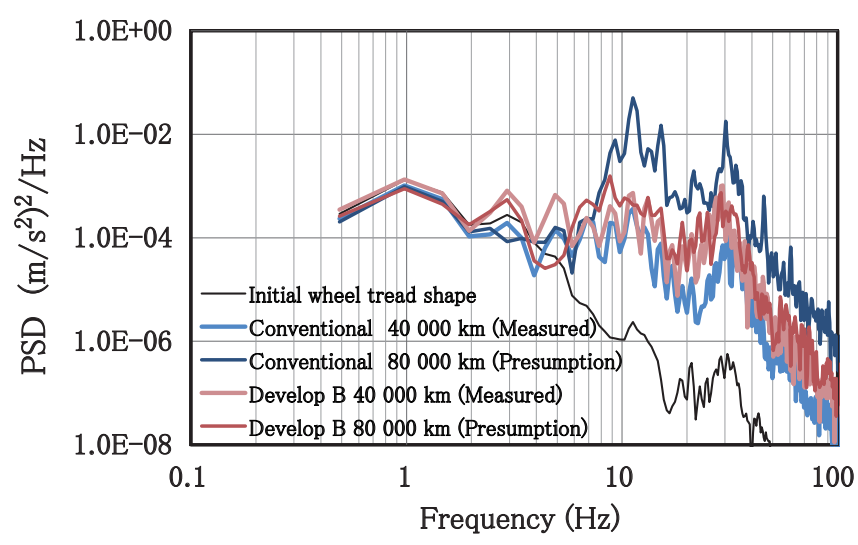

Fig. 16 Comparison of the analysis results for PSD

vibration is shown in Fig. 16 for a bogie frame.

In the presumed tread shape after an $80000 \mathrm{~km}$ run, as for the conventional product, increased PSD after a 40 $000 \mathrm{~km}$ run focusing on a peak frequency of $11 \mathrm{~Hz}$ and 30 $\mathrm{Hz}$. In contrast, as for the developed shoe B, these peaks do not appear in the presumed tread shape after the 80 $000 \mathrm{~km}$ run, and there is no large difference between the PSD for a $40000 \mathrm{~km}$ run and after the $80000 \mathrm{~km}$ run. The results indicated that the inhibiting effect on the wheel concave wear produced by the developed shoe B certainly contributes to running stability.

\section{Conclusions}

The elastic structure type composition brake shoe that was developed was able to maintain the brake performance under wet conditions and reduce the damage to the wheel due to a reduction in heat load, and has an effect on controlled wheel concave wear. With these outstanding characteristics, the developed brake shoe should, in addition to ensuring safety, also improve running stability through appropriate maintenance of the wheel tread shape and reduce the maintenance costs as wheels need to be replaced less frequently.

\section{Acknowledgement}

The authors would like to express their sincere gratitude to Ueda Brake Inc. for development and manufacture of the brake shoe, and Shikoku Railway Company for the running tests.

\section{References}

[1] Kazuyuki, H., Fumiko, M., Shinya, F., and Hideshi, K., "Mechanism and countermeasure of wheel tread thermal cracking," RTRI Report, Vol. 25, No. 10, pp. 23-28, 2011 (in Japanese).

[2] Kenji, S., Eisaku, S., Takayuki, S., Akihiro, H., and Shinichi, O., "Wheel wear tendency and vehicles dynamics in new style commuter trains," RTRI Report, Vol. 21, No. 7, pp. 45-50, 2007 (in Japanese). 
[3] Jyunichi, N. and Takayuki, S., "Three-dimensional search technique for wheel / rail contact position,"

Authors

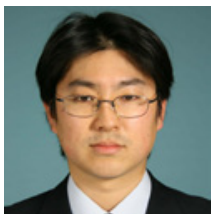

Shinichi SAGA

Assistant Senior Researcher, Brake Control

Laboratory, Vehicle Control Technology

Division

Research Areas: Thermal dynamics of braking, Adhesion of rail and wheel

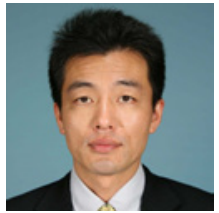

Yasushi KARINO

Senior Researcher, Brake Control Laboratory, Vehicle Control Technology Division Research Areas: Friction phenomenon of braking, Mechanics of brake device
RTRI Report, Vol. 25, No. 1, pp. 21-26, 2011 (in Japanese).

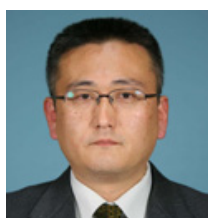

Akihiro HAGA

Senior Researcher, Vehicle Dynamics

Laboratory, Vehicle Structure Technology

Division

Research Areas: Riding comfort, Maintenance of wheel tread shape

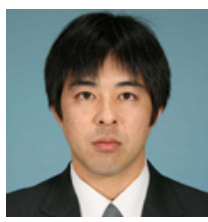

Junichi NAKAHASHI

Senior Researcher, Vehicle Dynamics

Laboratory, Vehicle Structure Technology

Division

Research Areas: Vehicle dynamics and

oscillation, Contact analysis of rail and wheel 